\title{
Rancang Bangun Arsitektur Modular Album Foto Digital 'Fotokita' berbasis Desktop
}

\author{
A. Heynoum Dala Rif'at, Rizky Januar Akbar, dan R.V. Hari Ginardi \\ Jurusan Teknik Informatika, Fakultas Teknologi Informasi, Institut Teknologi Sepuluh Nopember (ITS) \\ J1. Arief Rahman Hakim, Surabaya 60111 Indonesia \\ e-mail: rizky@if.its.ac.id
}

\begin{abstract}
Abstrak-Seiring dengan fenomena semakin maraknya aktifitas pengabadian momen, dibutuhkannya teknologi yang memadai untuk mendukung aktifitas tersebut. Beberapa solusi telah ditawarkan oleh percetakan atau studio foto untuk menawarkan jasa membuat album foto. Tetapi di Indonesia belum ada aplikasi album digital berbasis desktop yang dapat memudahkan pengguna secara langsung untuk membuat album fotonya sendiri.

Pada makalah ini, permasalahan tersebut akan ditangani dengan membuat album foto digital yang bersifat modular yang dapat mengakomodasi kebutuhan pengguna dan ketidakpastian perkembangan fitur di masa depan, misalnya penambahan frame, efek dan tools pada aplikasi. Perangkat lunak ini bersifat desktop dan terdapat abstraksi/aturan yang perlu diimplementasikan agar modul dapat diintegrasi. Perangkat lunak akan dapat menambah, menghapus instalasi atau mengubah status modul-modul dari album foto digital tersebut tanpa melakukan perubahan pada modul lain.

Pengujian dilakukan dengan melakukan penambahan, penghapusan instalasi dan pengubahan status modul. Dari hasil pengujian, aplikasi yang dirancang dan diimplementasikan telah memenuhi semua kebutuhan fungsional.
\end{abstract}

Kata Kunci-Album Foto Digital, Perangkat Lunak Modular

\section{PENDAHULUAN}

$\mathrm{P}$ ERKEMBANGAN teknologi di bidang digital sudah berkembang dengan sangat pesat, terutama dalam bidang fotografi. Dalam hal mencetak foto, yang dulu harus menggunakan film dan kemudian mencetaknya melalui proses yang rumit, sekarang bisa dilakukan dengan sangat mudah dengan memindahkan berkas yang ada di dalam kartu memori ke dalam komputer dan mencetaknya pun hanya membutuhkan sebuah mesin cetak (printer) dan kertas foto, dan foto-foto tersebut lalu diletakkan ke dalam album foto. Proses tersebut pada saat ini dapat dilakukan dengan menggunakan komputer melalui aplikasi.

Seiring dengan fenomena semakin maraknya pengabadian momen, dibutuhkannya teknologi yang memadai untuk mendukung kebutuhan. Beberapa percetakan atau studio foto sudah menyediakan layanan untuk melakukan pengeditan foto dan album, tetapi terkadang hasil yang ada tidak sesuai dengan harapan klien dan memakan biaya lebih. Solusi untuk klien yang menginginkan untuk mencetak foto album sesuai dengan selera masing-masing sudah tersedia, tetapi untuk di Indonesia sendiri sarana yang tersedia masih berupa pengeditanalbum foto secara online, sedangkan kecepatan jaringan belum bisa dikatakan mampu untuk melakukan semua kegiatan secara online.

Aplikasi album foto digital berbasis desktop diperlukan untuk memudahkan pengerjaan tersebut. Selain itu, untuk dapat menarik perhatian pengguna, sebuah aplikasi harus mengikuti perkembangan zaman dan mode, dan dikarenakan adanya ketidakpastian perkembangan fitur, misalnya penambahan frame, layout, efek dan tema sesuai dengan kebutuhan dan selera pengguna, maka dibutuhkan aplikasi album foto digital yang modular, dimana nantinya modul-modul dalam album foto digital dapat diperbaharui, dihapus, atau diganti dengan mudah.

Tujuan dikembangkannya aplikasi ini adalah untuk memberikan solusi kemudahan dalam melakukan evolusi dan modularitas sistem, sehingga dapat mengakomodasi kebutuhan pengguna kedepannya.

\section{TINJAUAN PUSTAKA}

\section{A. Album Foto Digital}

Album foto digital adalah sekumpulan foto yang dibukukan dalam suatu wadah. Album foto digital yang digital adalah aplikasi perangkat lunak dimana pengguna dapat memindahkan berkas foto dari hardisk ke dalam basis data utama aplikasi tersebut. Perangkat lunak Album foto digital biasanya memungkinkan pengguna untuk melihat, mengubah, dan mengatur foto dengan menggunakan antarmuka buku seperti yang menyerupai album foto tradisional.

Pada saat ini di Indonesia sudah terdapat beberapa usaha yang bergerak dalam bidang album foto digital seperti Photobook Indonesia ${ }^{1}$ Picbit Photobook $^{2}$ dan SnappyPhotobook ${ }^{3}$ tetapi masih terdapat beberapa kekurangan, yaitu:

- Editor berbasis web sehingga membutuhkan koneksi internet untuk mengedit album foto.

- Waktu untuk memuat halaman editor relatif lama sehingga tidak memungkinkan untuk mengedit foto dengan koneksi internet yang lambat.

\footnotetext{
${ }^{1} \mathrm{http}: / /$ www.photobookindonesia.com/

${ }^{2}$ http://picbitphotobook.com/
}

\footnotetext{
${ }^{3}$ http://www.snapyphotobook.com/site/
} 


\section{B. Modularitas}

Secara umum, pemrograman yang modular adalah teknik perancangan perangkat lunak yang menekankan kepada pemisahan fungsi program ke modul-modul yang mandiri yang dapat dintegrasikan ke aplikasi yang lebih besar.

Menurut sudut pandang ilmu teknik, modularitas secara umum memiliki tiga tujuan, yaitu:

- Untuk mengelola kompleksitas suatu pengembangan

- Untuk memungkinkan pengerjaan secara pararel

- Untuk mengakomodasi ketidakpastian yang akan terjadi di masa depan.

Modularitas mengakomodasi ketidakpastian yang akan terjadi di masa depan karena elemen tertentu pada rencang bangun modular dapat diubah selama aturan-aturan perancangan ditaati. Oleh karena itu, dalam arsitektur modular, modul baru dapat mengganti modul lama dengan mudah dan dengan biaya yang rendah [1].

Modularitas terdiri dari dua aspek: model runtime dan model development. Model runtime fokus kepada bagaimana mengatur sistem perangkat lunak pada saat runtime, sementara model development adalah bagaimana para pengembang menggunakan kerangka kerja untuk membangun perangkat lunak mereka.

Dalam pembuatan modularitas pada album foto digital ini, pemrograman berbasis interface (interface-based programming) diperlukan. Pemrograman berbasis interface adalah pola arsitektur untuk melaksanakan pemrograman modular pada tingkat komponen dalam bahasa pemrograman berorientasi objek yang tidak memiliki sistem modul, sebagai contoh Java. Java tidak memiliki sistem modul pada tingkat komponen. Java memiliki sistem package, tetapi komponen perangkat lunak Java biasanya terdiri dari beberapa packages Java. Pemrograman berbasis interface memberikan keuntungan.

Interface modul menyatakan unsur-unsur yang akan disediakan dan dibutuhkan oleh modul. Implementasinya berupa kode yang bekerja yang merespon unsur-unsur yang terdapat pada interface.

\section{Java Service Loader}

Kelas ServiceLoader merupakan kelas dari java.util yang dapat membaca konfigurasi berkas yang tersimpan dalam berkas arsip Java (JAR) dan menemukan implementasi dari sebuah implementasi, kemudian membuat implementasi tersebut tersedia sebagai daftar objek untuk dipilih [2]. Untuk tujuan pemuatan, service direpresentasikan oleh satu jenis interface atau abstract class tunggal. Concrete class juga dapat digunakan, tetapi tidak direkomendasikan. Sebuah penyedia service mengandung satu atau lebih concrete class yang mengextend tipe servis ini dengan data dan kode yang spesifik kepada penyedia [3].

Kelas penyedia biasanya tidak bukan seluruh penyedia itu sendiri melainkan proksi yang berisi informasi yang cukup untuk menentukan apakan layanan mampu memenuhi permintaan tertentu bersama dengan kode yang dapat membuat penyedia yang sebenarnya pada permintaan.

\section{Java Standard Widget Toolkit (SWT)}

Standard Widget Toolkit (SWT) adalah sebuah widget toolkit grafis yang digunakan pada platform Java. SWT Java merupakan salah satu alternatif untuk menampilkan elemen GUI selain Java Absract Window Toolkit (AWT) dan Swing.

Untuk menampilkan elemen GUI, implementasi SWT mengakses pustaka asli GUI dari sistem operasi menggunakan JNI (Java Native Interface). Program yang menggunakan SWT portabel, tetapi implem entasi dari toolkit unik pada setiap platform [4].

\section{E. Java Properties}

Kelas properti pada java merupakan satu set yang persistent dari properti. Properti dapat disimpan dan dimuat dari sebuah stream. Setiap kunci dan nilai yang dikandung dalam daftar properti adalah string [5]. Kelas properti merupakan kelas yang aman dari thread. Beberapa thread dapat berbagi properti tunggal tanpa perlu sinkronisasi eksternal.

Kelas properti digunakan oleh banyak kelas yang lain [6]. Beberapa metode dan konstruktor pada properti yang digunakan pada tugas akhir ini adalah:

- Properties()

- String getProperty(String key)

- void load(InputStream streamIN) throws IOException

- Object setProperty(String key, String value)

- void store(OutputStream streamOut, String description)

\section{ANALISIS DAN PERANCANGAN SISTEM}

\section{A. Analisis}

Fotokita terdiri dari dua platform yaitu desktop dan website. Aplikasi berbasis desktop berfungsi sebagai editor foto album dan website berfungsi untuk menangani proses bisnis yang terjadi antara pelanggan dan percetakan dalam proses pencetakan album foto.

Fotokita modular merupakan perangkat lunak yang mengintegrasikan modul-modul bawaan pada aplikasi Fotokita yaitu modul frame, modul tool dan modul efek. Fitur administratif perangkat lunak utama merupakan fitur bagi pengguna untuk menambah modul, menghapus instalasi modul dan mengaktifkan/mengnonaktifkan modul.

Kasus penggunaan pada aplikasi ini adalah menambah modul, menghapus instalasi modul dan mengubah status modul seperti pada Gambar 1.

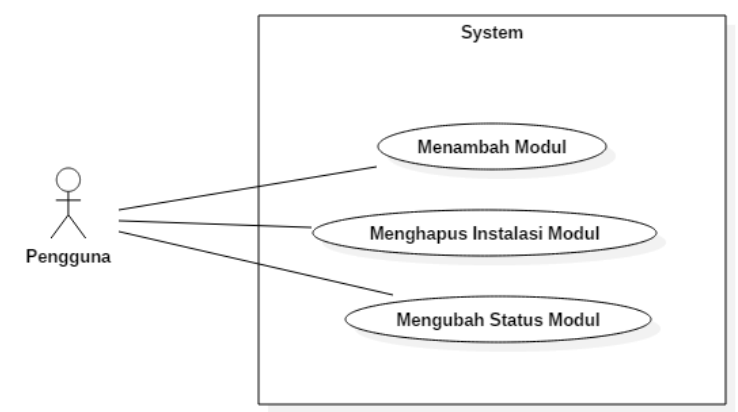

Gambar 1. Diagram kasus penggunaan. 


\section{B. Perancangan Interface Fotokita}

Fotokita merupakan aplikasi standalone yang dapat dijalankan mandiri. Untuk membuat class diagram dan juga menentukan bagian apa saja yang bisa dijadikan plugin dan juga atribut yang dibutuhkan untuk mengembangkan modul, rancangan aplikasi Fotokita dipecah menjadi beberapa bagian. Secara umum, fotokita memiliki tampilan antarmuka seperti pada Gambar 2.

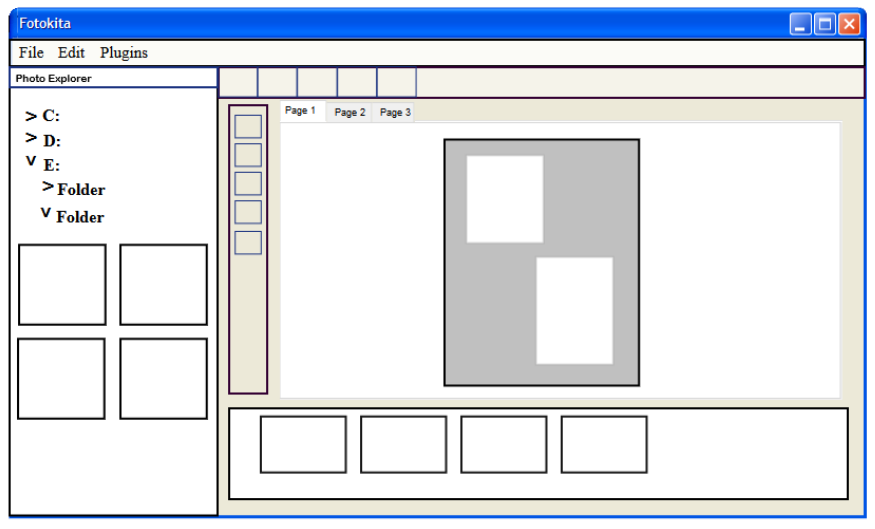

Gambar 2. Rancangan Antarmuka Album Foto Digital Fotokita

Album Foto Digital Fotokita dapat dibagi menjadi beberapa bagian yaitu menubar, toolbar, toolbox, photo explorer, project explorer dan obyek yang bisa diletakkan pada page. Setiap bagian dapat dipecaha menjadi bagian-bagian kecil lagi. Menubar memiliki menu dan menu items, toolbox terdiri dari tools, obyek yang bisa diletakkan pada page adalah frame, layout dan foto. Masing-masing bagian beserta pecahannya dibuatkan interface.

\section{Perancangan Modularitas}

Daur hidup modul pada Fotokita ditunjukkan pada Gambar 3. Daur hidup modul pada Fotokita adalah installed, enabled, disabled dan uninstalled. Installed adalah kondisi ketika modul sudah berhasil dipasang, enabled adalah kondisi ketka modul terpasang dan aktif, disabled adalah kondisi ketika modul terpasang tetapi tidak aktif dan uninstalled adalah kondisi ketika modul telah terhapus instalasinya.

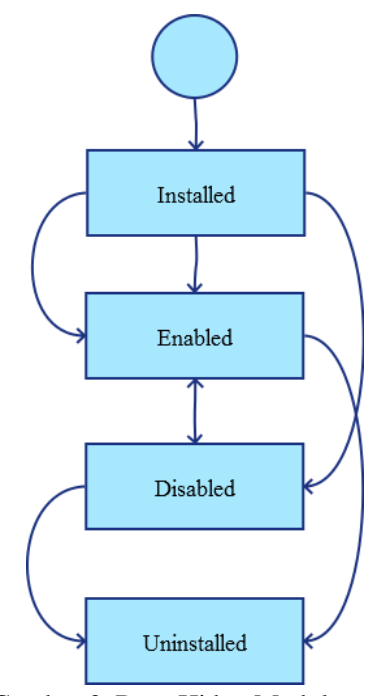

Gambar 3. Daur Hidup Modul
Modul yang dikembangkan wajib memiliki komponen yang mendefinisikan properti modul. Modul akan menggunakan beberapa kelas pada perangkat lunak utama. Karena itu, modul memiliki ketergantungan/dependensi dengan komponen lain dari perangkat utama. Komponen yang menjadi dependensi yaitu:

1. fotokita.plugin

Modul yang dibuat wajib memiliki suatu kelas yang merealisasikan kelas interface IModulPlugin (jika modul enhancement maka merealisasikan kelas interface IEnhancementPlugin) dan kelas IPlugin.

2. fotokita.widget.edit.enhancement

Efek yang dibuat wajib memiliki satu kelas yang mengimplementasikan kelas abstrak efek yang berada pada komponen ini.

3. Fotokita.widget.tool.toolbox

Tool yang dibuat wajib memiliki satu kelas yang mengimplementasikan kelas abstrak tool yang berada pada komponen ini.

\section{Perancangan Data}

Dengan menggunakan Java Properties, setiap berkas arsip java yang berhasil dipasang pada aplikasi akan memiliki satu berkas properties yang berisi beberapa data yang dijelaskan pada Tabel 1.

Tabel 1.

Perancangan Berkas Properties

\begin{tabular}{cl}
\hline \hline Nama Property & \multicolumn{1}{c}{ Keterangan } \\
\hline pluginName & Nama berkas arsip java \\
pluginPath & Direktori berkas arsip java \\
enabled & Modul terpasang atau tidak terpasang \\
active & Status modul \\
\hline \hline
\end{tabular}

\section{IMPLEMENTASI}

\section{A. Lingkungan Implementasi}

Dalam merancang perangkat lunak ini digunakan beberapa perangkat pendukung yang terdiri dari perangkat keras dan perangkat lunak.

Spesifikasi perangkat keras yang digunakan dalam membangun web layanan transaksi photobook adalah sebagai berikut:

Tipe $\quad$ : HP Pavilion 7

Prosesor $\quad:$ Int el $@$ Core $^{\mathrm{TM}} \mathrm{i} 7-4510 \mathrm{U}$ CPU @ $2.00 \mathrm{GHz}$ Memori $\quad: 8.00 \mathrm{~GB}$ RAM

Sistem Operasi : Windows 8.1 Professional 64 bit

Perangkat lunak yang digunakan dalam Fotokita modular adalah sebagai berikut:

- Eclipse Mars digunakan sebagai IDE

- StarUML 2.7.0 digunakan untuk membuat digram kasus penggunaan, diagram aktivitas dan diagram kelas.

\section{B. Implementasi Proses Bisnis}

Gambar 4 menunjukkan diagram alir dari kasus penggunaan menambah modul. Ketika tombol add pada jendela manajemen modul ditekan, file dialog akan muncul dan menampilkan berkas yang mempunyai ekstensi .jar. Ketika berkas arsip Java dipilih dan tombol open ditekan, berkas arsip Java akan diperiksa terlebih dahulu apakah sudah memenuhi aturan modularitas dan/atau berkas tersebut belum ada, jika iya maka 
berkas tersebut akan disalin ke dalam folder Plugins/Modul pada proyek, dan jika tidak maka pesan error akan dimunculkan. Aplikasi juga akan membuat satu berkas properties yang berisi informasi berkas arsip Java tersebut, yaitu nama plugin, lokasi plugin, status plugin dan aktif/tidaknya plugin. Berkas properties ini berfungsi untuk manajemen modul.

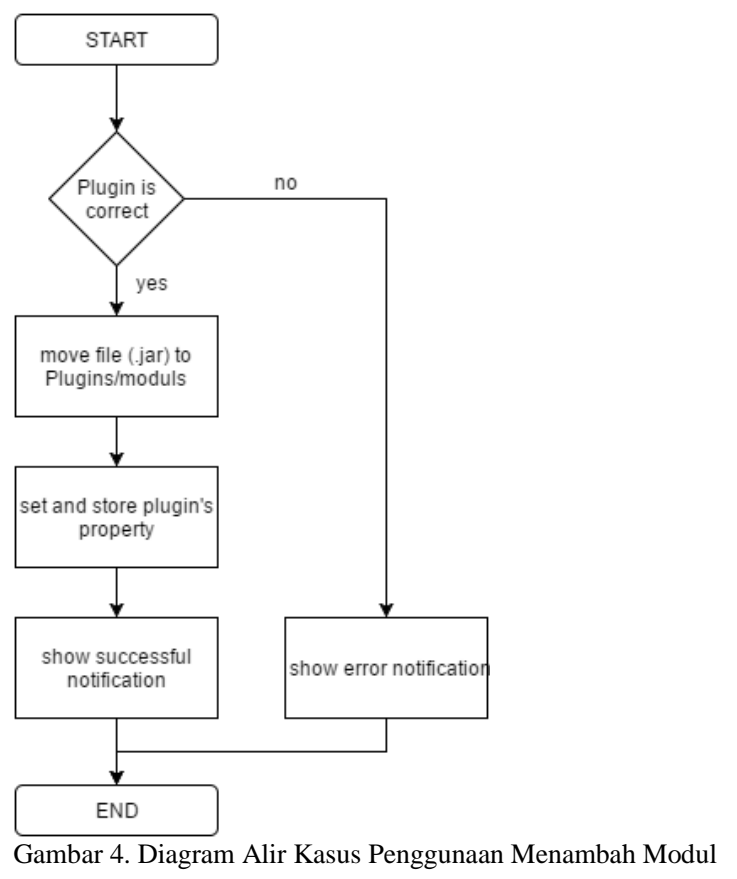

Gambar 5 menunjukkan diagram alir dari kasus penggunaan menghapus instalasi modul. Ketika salah satu baris dari dari tabel ditekan dan tombol uninstall pada jendela manajemen modul ditekan, sistem akan membuka berkas properties dari modul yang ingin dihapus instalasi, lalu akan merubah properti enabled menjadi no. Untuk melihat perubahan, aplikasi harus direstart ulang terlebih dahulu. Berkas arsip Java pada folder Plugins/Modul dapat dihapus oleh pengguna secara manual.

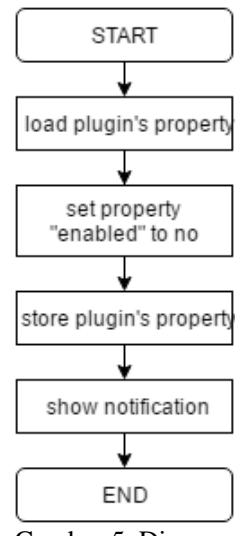

Gambar 5. Diagram Alir Kasus Penggunaan Menghapus Instalasi Modul

Gambar 6 menunjukkan implementasi dari kasus penggunaan mengubah status modul. Ketika salah satu baris dari tabel dipilih dan tombol change status ditekan, sistem memeriksa properti active pada berkas properties modul yang dipilih. Jika properti active bernilai true, nilai properti diubah menjadi false dan sebaliknya jika properti active bernilai false, nilai properti diubah menajdi true.

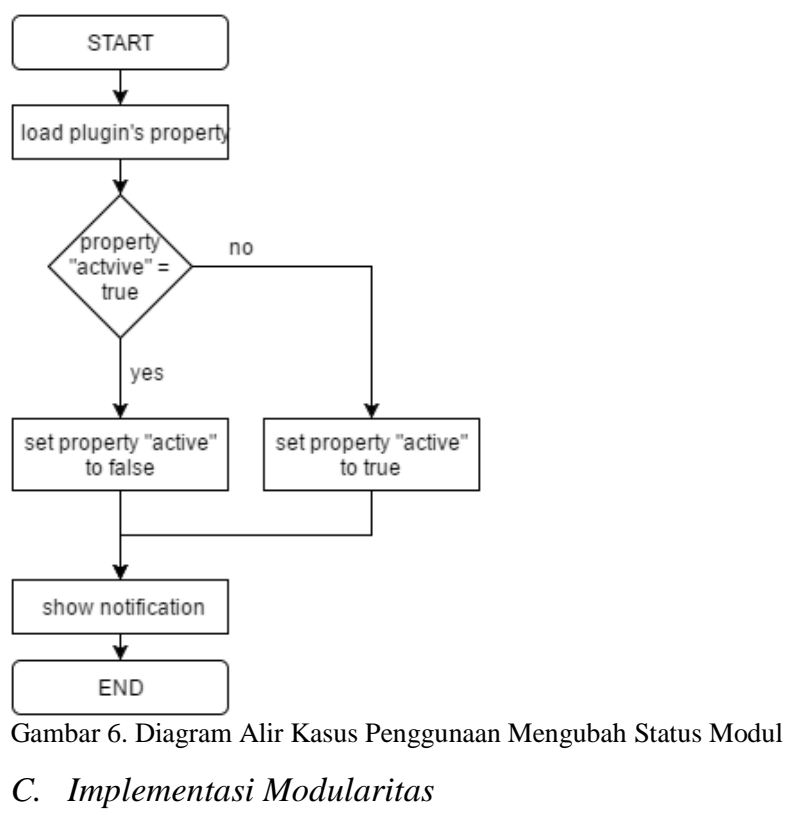

Penjelasan cara pembuatan modul meliputi aturan apa saja yang diperlukan sebuah modul agar dapat digabungkan dengan perangkat lunak utama dan langkah-langkah pembuatan modul yang mengikuti aturan-aturan yang telah dijelaskan.

Berikut aturan-aturan yang perlu diimplementasikan pada modul:

1. Modul wajib di-build sebagai berkas arsip Java (.jar).

2. Modul wajib memiliki satu kelas yang mengimplementasikan IEnhancementPlugin atau IToolPlugin.

3. Modul wajib memiliki satu berkas pada folder METAINF/Services yang berjudul plugins.IEnhancementPlugin, atau IToolPlugin yang berisi satu baris dengan nama package lengkap dengan kelas berkas yang akan diimplementasi.

4. Pada project modul Fotokita.jar wajib untuk dimasukkan ke build path. Tetapi pada saat di-build, FotokitaPlugin.jar tidak wajib untuk ikut di arsipkan.

5. Penamaan berkas arsip java harus sesuai dengan nama pada fungsi getName().

6. Tidak boleh ada error pada project.

Adapun langkah-langkah untuk membuat modul adalah:

1. Membuat project baru pada Eclipse

2. Klik kanan pada project, pilih Build Path -> Configure Build Path

3. Pada tab Libraries menekan tombol Add External JARs dan memilih berkas Fotokita.jar

4. Membuat kode

5. Membuat folder META-INF/Services dengan nama berkas sesuai dengan modul yang ingin dibuat, plugins.IEnhancementPlugin untuk modul efek dan plugins.IToolPlugin untuk modul tool. Isi berkas tersebut berisi satu baris berisi nama kelas lengkap dengan package. Sebagai contoh untuk membuat text tool maka isi dari plugins.IToolPlugin adalah text.TextToolPlugin. 
6. Klik kanan pada project, pilih Export, lalu pilih JAR File sebagai export destination, lalu tekan tombol Next, dan centang package maupun berkas yang akan diekspor.

7. Pilih destinasi berkas, lalu klik tombol Finish.

Pembacaan berkas modul dilakukan pada kelas PluginManager dalam fungsi getEnhancementPlugins, getToolPlugins dan getFramePlugins yang masing-masing akan mengembalikan list yang berisi modul yang sesuai dengan aturan. Untuk modul frame, daftar frame tidak perlu dimuat karena berupa gambar (.png).

\section{PENGUJIAN DAN EVALUASI}

Pengujian yang dilakukan berupa pengujian fungsionalitas. Pengujian fungsionalitas dilakukan dengan model blackbox untuk menguji proses penambahan modul, proses penghapusan instalasi modul dan proses pengubahan status modul.

Uji coba fungsionalitas administratif adalah uji coba yang dilakukan terhadap fungsionalitas yang dapat dilakukan oleh pengguna. Uji coba dilakukan dengan metode black box yang artinya fungsionalitas diperiksa apakah terpenuhi atau tidak tanpa melihat struktur internal ataupun metode yang digunakan dalam pengerjaan fungsionalitas tersebut. Skenario pengujian ditunjukkan pada Tabel 2.

Tabel 2.

Skenario Pengujian

\begin{tabular}{|c|c|c|}
\hline Kasus Pengujian & Skenario & $\begin{array}{l}\text { Hasil yang } \\
\text { Diharapkan }\end{array}$ \\
\hline $\begin{array}{l}\text { Menambah } \\
\text { Modul }\end{array}$ & $\begin{array}{c}\text { Semua aturan modul sudah } \\
\text { terpenuhi } \\
\text { Ada aturan modul yang } \\
\text { tidak terpenuhi } \\
\text { Modul sudah terpasang }\end{array}$ & $\begin{array}{l}\text { Modul berhasil } \\
\text { didaftarkan } \\
\text { Modul gagal } \\
\text { ditambahkan } \\
\text { Modul berhasil } \\
\text { didaftarkan }\end{array}$ \\
\hline $\begin{array}{l}\text { Menghapus } \\
\text { Instalasi Modul }\end{array}$ & $\begin{array}{l}\text { Menghapus modul yang } \\
\text { sudah terpasang }\end{array}$ & Modul terhapus \\
\hline Mengubah Status & $\begin{array}{c}\text { Mengubah status menjadi } \\
\text { aktif }\end{array}$ & Modul aktif \\
\hline Modul & $\begin{array}{c}\text { Mengubah status menjadi } \\
\text { tidak aktif }\end{array}$ & Modul tidak aktif \\
\hline
\end{tabular}

Berdasarkan data pada Tabel 2, semua skenario pengujian berhasil dan program berjalan dengan baik. Sehingga bisa ditarik kesimpulan bahwa fungsionalitas dari program telah bisa bekerja sesuai dengan yang diharapkan dan menunjukkan hasil yang benar.

\section{KESIMPULAN}

Dari hasil pengamatan selama proses perancangan, implementasi dan pengujian perangkat lunak yang dilakukan, dapat diambil kesimpulan sebagai berikut:

1. Album foto digital Fotokita dibangun dengan menggunakan pemrograman berorientasi objek sehingga dapat dipecah menjadi elemen-elemen kecil sehingga bisa dibangun secara modular.

2. Modul yang dibangun harus memenuhi beberapa aturan tertentu agar bisa berfungsi pada sistem.

3. Daur modul pada Fotokita adalah installed, enabled, disabled dan uninstalled.

\section{DAFTAR PUSTAKA}

[1] K. Knoernschil, Java Application Architechture, Modularity Patterns with Examples Using OSGi, Indiana: Prentice Hall, 2013.

[2] "IBM Developer Works," IBM, [Online]. Available: http://www.ibm.com/developerworks/library/j-5things12/. [Accessed 31 May 2016].

[3] "Class ServiceLoader $<\mathrm{S}>$," Oracle, [Online]. Available: http://docs.oracle.com/javase/6/docs/api/java/util/ServiceLoader.html. [Accessed 31 May 2016].

[4] "Wikipedia - Standard Widget Toolkit," [Online]. Available: https://en.wikipedia.org/wiki/Standard_Widget_Toolkit. [Accessed 8 June 2016].

[5] "Properties (Java Platform)," Oracle, [Online]. Available: https://docs.oracle.com/javase/7/docs/api/java/util/Properties.html. [Accessed 8 June 2016].

[6] "Java - The Properties Class," [Online]. Available: http://www.tutorialspoint.com/java/java_properties_class.htm. [Accessed 8 June 2016]. 